\title{
DAMPAK PROGRAM KONVERSI MINYAK TANAH KE LPG TERHADAP DISTRIBUSI MINYAK TANAH BERSUBSIDI KE LPG ( Studi Kasus Di Pangkalan Kota Salatiga )
}

\author{
Oleh: \\ Joko Pramono \\ Dosen Tetap STIE AMA Salatiga \\ Gunanto \\ Dosen Tetap STIE AMA Salatiga
}

\begin{abstract}
Abstrak
Penelitian ini bertujuan untuk mengetahui dampak konversi minyak tanah ke LPG terhadap distribusi minyak tanah bersubsidi, studi kasus di Pangkalan kota Salatiga. Pada tahun 2008 di kota Salatiga terdapat 2 (dua) agen minyak tanah yang bertanggung jawab atas terpenuhinya kebutuhan minyak tanah bersubsidi dan terdapat 114 buah Pangkalan minyak tanah bersubsidi (sebelum ada konversi minyak tanah ke LPG yang ada di kota Salatiga) yang langsung melayani kepada masyarakat.

Di Kota Salatiga sebelum adanya program konversi ini mendapat kuota minyak tanah sebesar 865.000 liter per bulan guna memenuhi kebutuhan minyak tanah kepada masyarakat, yang selanjutnya di salurkan oleh 2 (dua) agen dan di 114 Pangkalan. Dari masing-masing pangkalan yang ada, mempunyai jatah sesuai dengan kebutuhan masyarakat yang ada di wilayahnya, sehingga kebutuhan masyarakat akan minyak tanah bisa terpenuhi.

Penelitian ini mengambil sampel sebanyak 35 pangkalan dengan kuota yang akan diterima sebesar 138.800 liter, dengan periode pengamatan bulan Juni - Juli 2008. Berdasarkan analisis data diketahui bahwa kuota distribusi minyak tanah yang diberikan dari agen (penyalur) sebesar 138.800 liter ke Pangkalan, realisasinya tidak sesuai dengan kuota yang ditetapkan, dimana jumlah realisasinya hanya sebesar 34.020 liter, lebih kecil dari kuota yang seharusnya diterima oleh Pangkalan, sehingga terjadi kekurangan pasokan sebesar 104.780 liter atau terjadi penyimpangan sebesar 75,49 \%. Hal ini akan menimbulkan dampak kelangkaan minyak tanah dan kenaikan harga diatas harga eceran tertinggi (HET) yang ditetapkan oleh Pemerintah.

Dengan demikian dapat disimpulkan bahwa adanya program konversi minyak tanah ke LPG mengakibatkan berkurangnya distribusi minyak tanah bersubsidi di Pangkalan Kota Salatiga.
\end{abstract}

Kata kunci : Dampak Konversi, Distribusi, Minyak Tanah, LPG. 


\section{A. PENDAHULUAN}

Program Konversi Minyak Tanah ke LPG (Liquefied Petroleum Gas) merupakan program Pemerintah yang bertujuan untuk mengurangi subsidi BBM (Bahan Bakar Minyak), dengan mengalihkan pemakaian minyak tanah ke LPG. Program ini diimplementasikan dengan membagikan paket tabung LPG beserta isinya, kompor gas dan perlengkapannya kepada rumah tangga dan usaha mikro pengguna minyak tanah. Untuk mengurangi dampak sosial atas diberlakukannya program ini, pendistribusian LPG dilakukan oleh eks Agen dan Pangkalan Minyak Tanah yang diubah menjadi Agen dan Pangkalan Elpiji 3 Kg. Program ini ditugaskan kepada Pertamina, berkoordinasi dengan Departemen terkait, dan direncanakan pelaksanaannya secara bertahap antara tahun 2007 - 2010 . Dalam rangka menjamin kelancaran dan keterjangkauan pelayanan dan pemenuhan kebutuhan minyak tanah bersubsidi dan LPG bagi masyarakat, perlu adanya Pengawasan dan Pemantauan penyaluran Bahan Bakar Minyak dan Gas dari penyimpangan distribusi, pelanggaran harga eceran tertinggi (HET), kelangkaan dan penyalahgunaan minyak tanah bersubsidi. Pengawasan bermaksud mengawasi pendistribusian minyak tanah bersubsidi dan Gas agar tepat sasaran efektif dan efisien, mengingat jumlah kebutuhan minyak tanah bersubsidi yang dibutuhkan masyarakat sangat terbatas.

Kebutuhan minyak tanah bersubsidi dan Gas diusulkan oleh Bupati/Walikota kepada Gubernur melalui Badan Koordinasi Pembangunan Lintas Kabupaten/Kota Propinsi Jawa Tengah untuk menentukan kebutuhan minyak tanah bersubsidi dan Gas di Daerah dengan menugaskan Tim Koordinasi Pengawasan dan Pengendalian Distribusi Bahan Bakar Minyak. Beberapa jenis permasalahan yang berpotensi terjadi adalah sebagai berikut :

1. Penyelewengan distribusi yaitu, penyimpangan penyaluran dari Instalasi / Depot, Agen, Pangkalan sampai dengan pengecer ke konsumen pemakai yakni apakah jumlah yang disalurkan sudah sesuai dengan kuota yang ditentukan .

2. Pelanggaran Harga Eceran Tertinggi (HET) yakni apakah dalam menentukan harga eceran tertinggi sudah sesuai dengan harga yang ditentukan oleh Pemerintah atau sampai dengan batas toleransi harga yang 
ditentukan. Batas harga eceran tertinggi yang diperbolehkan adalah harga penjualan minyak tanah di Pangkalan.

3. Kelangkaan minyak tanah adalah tidak terpenuhinya kebutuhan masyarakat sesuai dengan kuota yang diajukan Pemerintah Daerah .

4. Penyalahgunaan Minyak Tanah bersubsidi, yaitu pemakaian yang tidak sesuai dengan peruntukannya, misalnya minyak tanah untuk kebutuhan rumah tangga digunakan atau dijual untuk Industri, atau dicampur dengan bahan bakar lainnya.

Pengawasan distribusi minyak tanah bersubsidi adalah merupakan serangkaian kegiatan untuk mencari, mengumpulkan, mengolah data dan/atau keterangan lainnya untuk menguji kepatuhan dalam pendistribusian Minyak Tanah bersubsidi, hal ini merupakan salah satu upaya demi terwujudnya tata kelola Pemerintah yang baik (good governance).

\section{Perumusan Masalah}

Dalam penelitian ini Peneliti membuat rumusan masalah sebagai berikut :

Bagaimana Dampak Konversi Minyak Tanah ke LPG terhadap Distribusi Minyak Tanah Bersubsidi di Pangkalan Kota Salatiga?

\section{Tujuan dan Manfaat Penelitian}

Penelitian bertujuan untuk mengetahui dampak konversi minyak tanah ke LPG terhadap Distribusi Minyak Tanah Bersubsidi di Pangkalan Kota Salatiga. Sedangkan manfaat dari penelitian ini adalah :

1. Bagi Pemerintah Kota Salatiga, memberikan masukan akan dampak yang ditimbulkan oleh konversi minyak tanah ke LPG, sehingga Pemerintah Kota bisa mengambil kebijakan lebih lanjut.

2. Bagi perguruan tinggi sebagai tambahan khasanah pustaka dan ilmu pengetahuan.

\section{B. KAJIAN TEORI}

\section{a. Pengertian LPG}

LPG adalah kependekan dari Liquefied Petroleum Gas, merupakan gas hasil produksi dari kilang minyak atau kilang gas, yang komponen utamanya 
adalah gas propane $(\mathrm{C} 3 \mathrm{H} 8)$ dan butane $(\mathrm{C} 4 \mathrm{H} 10)$ yang dicairkan. Pertamina memasarkan LPG sejak tahun 1969 dengan merk dagang ELPIJI.

\section{b. Jenis LPG Berdasarkan Komposisi Propane dan Butane}

Berdasarkan komposisi propane dan butane, LPG dapat dibedakan menjadi tiga macam:

1. LPG propane, yang sebagian besar terdiri dari $\mathrm{C} 3$

2. LPG butane, yang sebagian besar terdiri dari $\mathrm{C} 4$

3. LPG Mix, yang merupakan campuran dari propane dan butane.

\section{c. Kegunaan LPG}

LPG butane dan LPG mix biasanya dipergunakan oleh masyarakat untuk bahan bakar memasak, sedangkan LPG propane biasanya dipergunakan di industri sebagai pendingin, bahan bakar pemotong, untuk menyemprot cat dan lainnya.

\section{d. Pengertian Saluran Pemasaran}

Mayoritas produsen bekerjasama dengan perantara pemasaran untuk mengenalkan dan membawa produknya ke pasar. Para perantara pemasaran selanjutnya membentuk sebuah saluran pemasaran (disebut juga saluran perdagangan atau saluran distribusi).

Saluran distribusi, kadang-kadang disebut saluran perdagangan atau saluran pemasaran, dapat didefinisikan dalam beberapa cara. Umumnya definisi yang ada memberikan gambaran tentang saluran distribusi ini sebagai suatu rute atau jalur.

David A. Revzan dalam bukunya berjudul Marketing Organization Trogh The Channel, Whole saling in Marketing Organization (New York: John Wiley \& Sons, Inc.1991, P.108- dikutip oleh C. Glenn Walters ) mengatakan bahwa :

Saluran merupakan suatu jalur yang dilalui oleh arus barang - barang dari produsen ke perantara dan akhirnya sampai pada pemakai

Definisi tersebut masih bersifat sempit, istilah barang (terdapat juga dalam difinisi dimuka) sering diartikan sebagai suatu bentuk fisik. Akibatnya, definisi ini lebih cenderung menggambarkan pemindahan jas-jasa atau kombinasi antara barang dan jasa. Selain membatasi barang yang disalurkan, 
definisi ini juga membatasi lembaga lembaga yang ada. Definisi yang bersifat luas tidaklah demikian : tetapi harus memasukan semua lembaga yang mempunyai kepentingan dalam saluran, dan harus cukup luas macam barang serta jasa yang disalurkan.

Definisi lain tentang saluran pemasaran ini dikemukakan oleh The American Marketing Association, yang menekankan tentang banyaknya lembaga yang ada dalam aliran / arus barang, asosiasi tersebut menyatakan bahwa :

Saluran merupakan suatu struktur unit organisasi dalam perusahaan dan luar perusahaan yang terdiri dari agen, dealer, pedagang besar dan pengecer, melalui mana sebuah komoditi produk, atau jasa dipasarkan.

Definisi kedua ini lebih luas dibandingkan dengan definisi yang pertama. Dengan memasukan itilah struktur, definisi ini mempunyai tambahan arti yang bersifat statis pada saluran, dan tidak dapat membantu untuk mengetahui tentang hubungan - hubungan yang ada antara masingmasing lembaga.

Dari kedua definisi tersebut bisa disimpulkan bahwa saluran distribusi merupakan sekelompok pedagang dan agen perusahaan yang mengkombinasikan antara pemindahan fisik dan nama dari suatu produk untuk menciptakan kegunaan bagi pasar tertentu.

\section{e. Memilih Saluran Pemasaran}

Saluran Pemasaran melaksanakan tugas memindahkan barang dari podusen ke konsumen. Hal ini dilakukan sebagai upaya untuk mengatasi kesenjangan waktu, tempat, dan pemilikan yang memisahkan barang dan jasa dari orang-orang yang membutuhkan.

Keputusan-keputusan saluran pemasaran merupakan salah satu diantara keputusan-keputusan yang paling kritis yang dihadapi manajemen.

Saluran yang dipilih sangat mempengaruhi semua keputusan pemasaran. Penetapan harga perusahaan tergantung pada apakah perusahaan menggunakan pedagang-pedagang besar atau butik-butik berkualitas tinggi. Tenaga penjualan perusahaan dan keputusan-keputusan periklanan tergantung pada beberapa banyak pelatihan dan motivasi yang diperlukan dealer. Lagi 
pula keputusan-keputusan saluran perusahaan meliputi komitmen-komitmen yang relatif berjangka panjang

\section{a. Saluran Distribusi}

Setelah barang selesai dibuat dan siap dipasarkan, tahap berikutnya dalam proses pemasaran adalah menentukan metode dan rute yang akan dipakai untuk menyalurkan barang tersebut ke pasar . hal ini menyangkut masalah penentuan strategi penyaluran, termasuk pemilihan saluran distribusi, penanganan secara fisik, dan distribusi fisik.

Saluran distribusi , kadang-kadang juga disebut saluran perdagangan menurut Basu Swastha (2000:190) dapat didefinisikan secara sederhana sebagai berikut :

Saluran distribusi suatu barang adalah saluran yang digunakan oleh produsen untuk menyalurkan barang tersebut dari produsen sampai ke konsumen atau pemakai industri .

Adapun lembaga-lembaga yang ikut ambil bagian dalam penyaluran barang adalah :

a. Produsen

b. Perantara ( pedagang dan agen)

c. Konsumen akhir atau pemakai industri.

Saluran distribusi ini merupakan suatu struktur yang menggambarkan alternative saluran yang dipilih, dan menggambarkan situasi pemasaran yang berbeda oleh berbagai macam atau lembaga usaha (seperti produsen, pedagang besar, dan pengecer ). Hal ini bisa dipertimbangkan sebagai fungsi yang harus dilakukan untuk memasarkan barang secara efektif. Sering pula terjadi persaingan diantara system distribusi dari produsen yang berbeda.

Apabila tujuan perusahaan adalah maksimisasi laba, pemilihan saluran pemasaran harus didasarkan pada estimasi tingkat penghasilan yang dapat menutup investasinya kapitalnya. Jadi, keputusan tentang investasi perlu juga dipertimbangkan dalam pemilihan saluran. 


\section{b. Dasar-dasar Ekonomi yang dipakai dalam Perdagangan Eceran}

Tidaklah sulit bagi seseorang untuk menjalankan kegiatan pedagang eceran ini, dan untuk berhentipun juga mudah. Besarnya jasa yang ditawarkan oleh seorang pengecer dapat mempengaruhi keadaan sosial dan ekonominya, seorang pengecer dapat lebih maju dalam usahanya apabila mau bekerja lebih baik dibandingkan dengan pesaingnya dalam melayani konsumen. Pelayanan kepada konsumen harus diutamakan karena merupakan tanggung jawab primer, sedangkan tanggung jawab sekundernya adalah melayani pedagang besar atau produsen.

Fungsi pengecer yang utama adalah memberikan pelayanan kepada konsumen agar pembeliannya bisa dilakukan dengan cara yang sangat mudah. Pengecer juga bertanggung jawab menyediakan berbagai macam produk yang baik dengan harga layak, adapun fungsi-fungsi pemasaran yang dilakukannya antara lain :

a. Pengangangkutan

c. Penyimpanan

d. Pembelanjaan.

Pengangkutan dan penyimpanan merupakan fungsi yang dilakukan oleh pengecer untuk menyediakan barang-barang secara cepat bilamana dibutuhkan oleh konsumen. Jadi, dalam kaitannya dengan fungsi-fungsi tersebut terdapat usaha-usaha untuk menciptakan faedah waktu (time utility) dan faedah tempat (Place Utility), sedangkan fungsi pembelanjaan dapat dilakukan dengan menawarkan pembayaran secara kredit kepada konsumen.

Sebagai penjual, pengecer ini memberikan saluran berbagai produsen dan pedagang besar dalam usahanya untuk mendekati konsumen. Tidak jarang pula ikut melakukan kegiatan periklanan, promosi penjualan , maupun personal selling untuk membantu penyaluran barang. Pengecer juga dapat bertindak sebagai orang yang memberikan informasi tentang konsumen kepada produsennya. Informasi tersebut terutama berupa keinginan dan kebutuhan konsumen, sehingga dapat diperkirakan tentang 
jenis dan jumlah permintaannya. Pengecer juga ikut membagi-bagi barang yang dihasilkan oleh produsen ke dalam jumlah yang lebih kecil sesuai dengan permintaan konsumen, disamping itu juga membantu dalam pernyortiran barang yang dijualnya.

Jadi secara terperinci fungsi-fungsi yang dilakukan oleh pengecer selain pengangkutan, penyimpanan dan pembelanjaan adalah :
a. Mencari Konsumen
b. Menjalankan kegiatan promosi
c. Memberikan informasi
d. Melakukan pengepakan atau pembungkusan
e. Mengadakan penyortiran.

\section{c. Aliran dan Fungsi Saluran Pemasaran}

Sebuah saluran pemasaran bertugas memindahkan barang dari produsen ke konsumen. Dia mengatasi kesenjangan waktu, tempat, dan kepemilikan yang memisahkan barang dan jasa dari pihak yang ingin menggunakan. Anggota-anggota dalam saluran pemasaran melakukan sejumlah fungsi kunci dan berperan dalam aliran pemasaran berikut :

a. Informasi, yaitu pengumpulan dan penyebaran informasi riset pemasaran tentang pelanggan, pesaing, dan pemain dan kekuatan lain yang ada dan yang potensial dalam lingkungan pemasaran.

b. Promosi, yaitu pengembangan dan penyebaran komunikasi persuasive tentang desain tawaran untuk menarik konsumen.

c. Negosiasi, yaitu usaha untuk mencapai persetujuan akhir tentang harga dan hal- hal lain sebagai upaya transfer kepemilikan dapat dipengaruhi.

d. Pesanan, yaitu komunikasi kebelakang tentang maksud membeli oleh anggota anggota saluran pemasaran kepada manufaktur.

e. Pembiayaan, yaitu akuisisi dan alokai dana yang diperlukan untuk membiayai persediaan pada tingkat saluran pemasaran yang berbeda.

f. Pengambil Resiko, yaitu ssumsi resiko yang berhubungan dengan kerja penyalur. 
g. Kepemilikan Fisik, yaitu penyimpanan dan perpindahan produk fisik dari bahan baku sampai dengan pelanggan akhir.

h. Pembayaran, yaitu pembeli membayar tagihannya melalui Bank dan lembaga keuangan lainnya kepada penjual.

i. Hak, yaitu transfer aktual kepemilikan dari satu orang atau organisasi ke lainnya

Fungsi dan aliran tersebut terdaftar dalam pesanan normal yang timbul antara dua anggota penyalur. Beberapa aliran adalah aliran ke depan (Forward flows) : Kepemilikan fisik, hak dan promosi; lainnya adalah aliran ke belakang (Backward flows) : pemasaran dan penyaluran dan sisanya bergerak ke depan dan ke belakang (: Informasi, negosiasi, pembiayaan, dan pengambilan resiko). Apabila semua aliran tersebut digabung dalam satu diagram, rumitnya saluran pemasaran yang paling sederhanapun akan jelas kelihatan.

\section{KERANGKA PEMIKIRAN}

Agar arah penelitian dapat direncanakan dan ditetapkan secara jelas, maka peneliti menyusun kerangka pemikiran sebagai berikut :

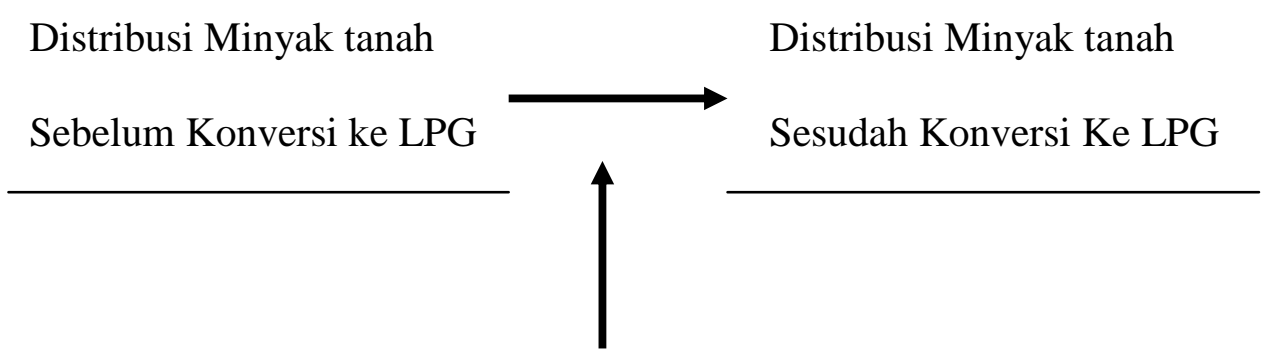

Gambar 1 : Kerangka Pemikiran

Dalam penelitian ini hipotesis yang dikemukakan adalah :

"Terdapat pengaruh adanya program konversi minyak tanah ke LPG terhadap Distribusi Minyak Tanah Bersubsidi di Pangkalan Kota Salatiga". 


\section{METODE PENELITIAN}

A. Tipe Penelitian

Penelitian ini menggunakan tipe penelitian diskriptif korelasional yaitu suatu tipe penelitian yang menerangkan tentang keterkaitan antara variabel yang satu dengan variabel lainnya untuk melihat perbedaan yang ada.

B. Populasi dan Sampel

Jumlah keseluruhan Pangkalan yang ada di kota Salatiga adalah 144 buah, dari jumlah tersebut diambil sampel sebanyak 35 buah Pangkalan. Pengambilan sampel dengan menggunakan teknik Proportionate Stratified Random Sampling.

C. Jenis Data dan Sumber Data

Penelitian ini menggunakan data primer, yaitu data yang diperoleh secara langsung dari Distributor di Pangkalan Salatiga dan data sekunder, yaitu data yang diperoleh dari Disperindag Salatiga.

D. Metode Pengumpulan Data

Data diperoleh melalui observasi, wawancara dan studi kepustakaan

E. Definisi Konsep

1. Bahan Bakar Minyak Tanah Bersubsidi

Minyak tanah bersubsidi menurut Peraturan Gubenur Jawa tengah nomor 44 tahun 2007 tentang pedoman pengawasan distribusi minyak tanah bersubsidi adalah bahan bakar minyak tanah yang standar dan mutunya (spesifikasi), harga, volume dan konsumennya ditentukan sesuai dengan perundang-undangan yang berlaku.

Misalnya harga minyak tanah bersubsidi menurut Peraturan Gubenur Jawa Tengah nomor 28 tahun 2008, tentang penetapan harga eceran tertinggi (HET) minyak tanah di pangkalan yang ada di kota Salatiga Rp 2.820,- per liter yang komposisinya dari harga di instalasi Pertamina Rp 2.500 ,- ditambah ongkos angkut Rp 100,- ditambah marjin agen Rp 70 ,- dan margin pangkalan Rp 120 ,-. 
2. Agen / Penyalur

Agen menurut Peraturan Gubenur jawa Tengah nomor 44 tahun 2007 tentang pedoman pengawasan distribusi minyak tanah bersubsidi adalah usaha untuk menyalurkan minyak tanah bersubsidi yang ditunjuk oleh badan usaha yang diberi penugasan untuk mendistribusikan minyak tanah bersubsidi ke pangkalan-pangkalan pada wilayah tertentu.

Misalnya harga minyak tanah bersubsidi menurut Peraturan Gubenur Jawa Tengah nomor 8 tahun 2008, tentang penetapan harga eceran tertinggi (HET) minyak tanah di Agen yang ada di kota Salatiga adalah sebesar $\operatorname{Rp} 2.670,-$.

3. Pangkalan

Pangkalan menurut Peraturan Gubenur jawa Tengah nomor 44 tahun 2007 tentang pedoman pengawasan distribusi minyak tanah bersubsidi adalah usaha untuk menyalurkan minyak tanah bersubsidi yang ditunjuk oleh Bupati/Walikota, diberi penugasan untuk mendistribusikan minyak tanah bersubsidi ke konsumen rumah tangga dan usaha kecil di wilayah tertentu.

Misalnya harga minyak tanah bersubsidi menurut Peraturan Gubenur JJawa Tengah nomor 8 tahun 2008, tentang penetapan harga eceran tertinggi (HET) minyak tanah di pangkalan yang ada di kota Salatiga adalah sebesar $\operatorname{Rp} 2.820,-$.

4. Dampak

Dampak adalah suatu akibat dari kegiatan yang dilakukan, sehingga akibat tersebut bisa berdampak positip maupun negatip, seperti disini akibat dari konversi distribusi bahan bakar minyak tanah ke Gas LPG akan menimbulkan dampak adanya kelangkaan minyak tanah , kenaikan harga minyak tanah dan mungkin belum siapnya masyarakat miskin untuk menggunakan bahan bakar Gas. Selain itu mungkin masyarakat miskin berkeberatan dengan pembelian bahan bakar gas karena harus membeli secara paket, tidak bisa mebeli secara eceran sesuai dengan kemampuan masyarakat miskin tersebut 


\section{Konversi}

Konversi adalah perubahan atas benda untuk menggantikan benda yang lain, hal ini timbul karena adanya faktor-faktor lain, dengan penggantian minyak tanah ke gas . Seperti konversi minyak tanah ke Gas, berarti penggantian bahan bakar minyak tanah ke Gas dikarenakan adanya kelangkaan sumberdaya bahan baku minyak tanah sehingga sebagai gatinya adalah LPG, diharapkan dengan konversi ini masyarakat akan lebih mudah untuk mendapatkan bahan bakar, serta bisa menghemat biaya.

E. Metode Analisis Data

Untuk menganalisis data peneliti menggunakan metode kuantitatif yaitu menggunakan uji beda dengan uji t-tes untuk sampel berhubungan dengan menggunakan rumus sebagai berikut :

\section{UJI BEDA}

\section{T-TES Untuk Sampel Berhubungan}

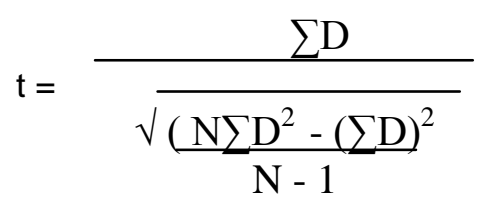

$\mathrm{D}=$ perbedaan semua pasangan

Dengan demikian, untuk mendapatkan nilai t-tes terlebih dahulu harus dihitung besarnya rata-rata hitung perbedaan semua pasangan (D) .

Selanjutnya pengujian hipotesis dilakukan berdasarkan $\mathrm{t}$ - test beda dua rata-rata (: distribusi minyak tanah sebelum program konversi dan distribusi minyak tanah sesudah program konversi) dengan tingkat signifikansi $5 \%$. Hipotesis diterima bila $\mathrm{t}$ - hitung lebih besar dari pada $\mathrm{t}$ - tabel atau bisa dideskripsikan dalam simbol sebagai berikut :

Ho $: \mu 1=\mu 2$

Hi $\quad: \mu 1 \neq \mu 2$

$\mu 1=$ sebelum program konversi ; $\mu 2=$ sesudah program konversi

Pengujian dua arah, sehingga $\mathrm{t}$ tabel diperoleh dari $\mathrm{t} \alpha / 2$

$\mathrm{Df}=\mathrm{n}-1$ atau $\mathrm{t}$ tabel $=\mathrm{t}(0,025 ; 35-1)$, diperoleh angka tabel 2,032 


\section{E. HASIL PENELITIAN DAN PEMBAHASAN}

\section{A. Gambaran Umum Obyek Penelitian}

Wilayah kota Salatiga terletak di Perbatasan Kabupaten Semarang dan Kabupaten Boyolali, Kota Salatiga terdiri dari 4 (empat) Kecamatan dan 22 (dua puluh dua) Kelurahan. Untuk melakukan kegiatan Distribusi minyak tanah bersubsidi, Walikota Salatiga menugaskan kepada Instansi teknis yaitu Dinas Perindustrian dan Perdagangan.

Dinas Perindustrian dan Perdagangan Kota Salatiga adalah suatu Instansi Pemerintah yang ada di kota Salatiga, yang tugas dan fungsinya adalah membantu pekerjaan Walikota yang berhubungan dengan tugas pokok dan fungsinya.

Di Dinas Perindustrian dan Perdagangan dalam struktur organisasinya dipimpin oleh seorang Kepala Dinas, dan membawahi 3 (tiga) bidang, yaitu bidang perindustrian, bidang perdagangan dan bidang pengendalian dan pengawasan industri dan perdagangan serta 1(satu) sub bagian tata usaha. Dimana masing-masing bidang membawahi 2 ( dua) seksi . Untuk pembagian tugas masing-masing bidangnya adalah sebagai berikut :

1. Bidang Perindustrian, tugasnya adalah membina sektor industri kecil, menengah dan besar, yang terkait perijinan, produksi dan bimbingan dan penyuluhan.

2. Bidang Perdagangan, tugasnya adalah membina sektor perdagangan, yang terkait dengan perijinan, promosi, harga, dll.

3. Bidang Pengawasan dan Pengendalian Perdagangan dan Perindustrian, tugasnya adalah mengawasi barang beredar, distribusi barang dan pengawasan mutu produk barang industri.

4. Bagian Tata Usaha, tugasnya adalah mendukung administrasi secara keseluruhan yang ada di Dinas Perindustrian dan Perdagangan .

B. Deskripsi Data

1. Kebijaksanaan

Setelah ada program konversi minyak tanah ke LPG dalam upaya meningkatkan pemerataan dan kesejahteraan masyarakat, Pemerintah Kota Salatiga telah mengalokasikan kuota bahan bakar minyak tanah bersubsidi. 
Dengan maksud agar pemerataan dan kebutuhan bahan bakar minyak tanah bisa terpenuhi, maka diterbitkanlah Peraturan Gubenur Jawa tengah nomor : 28 Tahun 2008 tentang Pedoman Pengawasan Distribusi Minyak Tanah Bersubsidi dan Harga Eceran Tertinggi di Propinsi Jawa Tegah.

\section{Pelaksanaan}

Pelaksanaan pendistribusian bahan bakar minyak tanah bersubsidi kepada masyarakat di kota Salatiga yang penyalurannya dilaksanakan oleh 2 (dua) agen di Kota Salatiga melalui 35 sampel Pangkalan yang diteliti mendapatkan kuota sebesar sebagai berikut :

a. Kuota Distribusi Minyak Tanah Bersubsidi sebelum ada konversi ke LPG di Kota Salatiga

Tabel. 4.1

Daftar Penerimaan Kuota

Distribusi Minyak Tanah Bersubsidi sebelum Konversi ke LPG

\begin{tabular}{|l|l|l|r|}
\hline NO & \multicolumn{1}{|c|}{ NAMA PANGKALAN } & \multicolumn{1}{|c|}{ ALAMAT } & KUOTA (Liter) / BL \\
\hline 1 & Liong Song Fa & Jl. Diponegoro No. 87 & 1,600 \\
\hline 2 & Suwandi & Jl. Patimura 58 A & 12,800 \\
\hline 3 & Suparmi & Turusan Rt 03/07, Salatiga & 400 \\
\hline 4 & Kuat & Bancaan Tengah Rt 5/5 & 3,200 \\
\hline 5 & Sukrisno & Jl. Kalinyamat No. 60, Ktw & 6,000 \\
\hline 6 & Anshori & Pasar Blauran, F15 & 5,000 \\
\hline 7 & Rubiyem & Langen Rejo Rt 08/05, gdg & 2,000 \\
\hline 8 & Tohari & Jl. Kartini, 13, Salatiga & 4,000 \\
\hline 9 & Ninung & Jl. Suropati II/46 & 400 \\
\hline 10 & Yuniarti & Jl. Benoyo, 3, Ktw & 40,000 \\
\hline 11 & Joni & Jl. T. Pahlawan, Ktw & -600 \\
\hline 12 & Sri Mukti Wibawati & Jl. Bulusari Rt 03/06, tgrj & 3,600 \\
\hline 13 & Sri Mulyaningsih & Jl. Bungur 10 A, Klccg & 400 \\
\hline 14 & Sunardi & Cebongan Rt 05/02 & 1,400 \\
\hline 15 & Tuseno & Jl. Diponegoro, 124 A & 3,000 \\
\hline 16 & Wagiyanto & Jl. Diponegoro, 122 & 11,000 \\
\hline 17 & H. Hawari & Jl. T. Pahlawan, Rt 02/04 & 4,400 \\
\hline 18 & Dalimo & Jl. Cemara I/20, Rt 03/09 & 1,600 \\
\hline 19 & Slamet Rifai & Somopuro Lor 636, Rt 07/08 & 1,800 \\
\hline 20 & Umi & Bugel Rt 03/02, sltg & 400 \\
\hline 21 & H. Komsatun & Tingkir Tengah, Rt 03/07 & 3,200 \\
\hline 22 & Titik Hindun & Gendongan, Rt 03/01 & 3,200 \\
\hline 23 & Teguh & Gendongan, Rt 03/03 & \\
\hline & & & \\
\hline
\end{tabular}




\begin{tabular}{|l|l|l|r|}
\hline 24 & Sutrisno & Jl. Kalinyamat, 36-38, Ktw & 10,000 \\
\hline 25 & Eman Suleiman & Jl. Osamaliki 525 & 1,800 \\
\hline 26 & Suharyanto & Blondo Celong Rt 01/10 & 13,000 \\
\hline 27 & Gunawan & Jl. Baru 28/Lama 32 & 4,000 \\
\hline 28 & Sri Rohani/Kadiyoto & Bonsari & 1,600 \\
\hline 29 & Amini/Rumadi & Jl. Surowi Jayan 284 Rt 3/3 & 1,600 \\
\hline 30 & Sarjono & Klaseman Manunsari & 5,000 \\
\hline 31 & Usman Slamet & Pengilon Surowijayo 296 & 1,600 \\
\hline 32 & Salim & Cabean Rt 2/1 Mangunsari & 1,400 \\
\hline 33 & Yofron & Jl. A. Yani & 1,400 \\
\hline 34 & Adnan Safii & Jl. Dr. Muwardi 49a & 5,800 \\
\hline 35 & Suratmi & Jl. Imam Bonjol 752 & 1,800 \\
\hline \multicolumn{2}{|c|}{ J u m l a h } & & $\mathbf{1 3 8 , 8 0 0}$ \\
\hline
\end{tabular}

Sumber : Data Primer diolah

b. Daftar Realisasi Penerimaan Distribusi Minyak Tanah Bersubsidi sesudah konversi ke LPG

Tabel. 4.2

Daftar Realisasi Penerimaan

Distribusi Minyak Tanah Bersubsidi Sesudah Konversi Ke LPG

\begin{tabular}{|c|c|c|c|}
\hline NO & NAMA PANGKALAN & ALAMAT & REALISASI (Liter) /BL \\
\hline 1 & Liong Song $\mathrm{Fa}$ & Jl. Diponegoro No. 87 & \\
\hline 2 & Suwandi & Jl. Patimura 58 A & 8,200 \\
\hline 3 & Suparmi & Turusan Rt 03/07, Salatiga & \\
\hline 4 & Kuat & Bancaan Tengah Rt 5/5 & \\
\hline 5 & Sukrisno & Jl. Kalinyamat No. $60, \mathrm{Ktw}$ & 4,800 \\
\hline 6 & Anshori & Pasar Blauran, F15 & 1,760 \\
\hline 7 & Rubiyem & Langen Rejo Rt 08/05, gdg & \\
\hline 8 & Tohari & J1. Kartini, 13, Salatiga & 4,100 \\
\hline 9 & Ninung & Jl. Suropati II/46 & 400 \\
\hline 10 & Yuniarti & Jl. Benoyo, 3, Ktw & \\
\hline 11 & Joni & Jl. T. Pahlawan, Ktw & \\
\hline 12 & Sri Mukti Wibawati & Jl. Bulusari Rt 03/06, tgrj & \\
\hline 13 & Sri Mulyaningsih & J1. Bungur $10 \mathrm{~A}, \mathrm{Klccg}$ & \\
\hline 14 & Sunardi & Cebongan Rt 05/02 & \\
\hline 15 & Tuseno & Jl. Diponegoro, 124 A & 820 \\
\hline 16 & Wagiyanto & J1. Diponegoro, 122 & 2,460 \\
\hline 17 & H. Hawari & Jl. T. Pahlawan, Rt 02/04 & 820 \\
\hline 18 & Dalimo & Jl. Cemara I/20, Rt 03/09 & 4,100 \\
\hline 19 & Slamet Rifai & Somopuro Lor 636, Rt 07/08 & \\
\hline 20 & Umi & Bugel Rt 03/02, sltg & 820 \\
\hline 21 & H. Komsatun & Tingkir Tengah, Rt 03/07 & \\
\hline 22 & Titik Hindun & Gendongan, Rt 03/01 & 820 \\
\hline 23 & Teguh & Gendongan, Rt 03/03 & \\
\hline 24 & Sutrisno & Jl. Kalinyamat, 36-38, Ktw & 4,920 \\
\hline 25 & Eman Suleiman & Jl. Osamaliki 525 & 200 \\
\hline
\end{tabular}




\begin{tabular}{|l|l|l|r|}
\hline 26 & Suharyanto & Blondo Celong Rt 01/10 & 9,600 \\
\hline 27 & Gunawan & Jl. Baru 28/Lama 32 & 3,200 \\
\hline 28 & Sri Rohani/Kadiyoto & Bonsari & - \\
\hline 29 & Amini/Rumadi & Jl. Surowi Jayan 284 Rt 3/3 & - \\
\hline 30 & Sarjono & Klaseman Manunsari & - \\
\hline 31 & Usman Slamet & Pengilon Surowijayo 296 & - \\
\hline 32 & Salim & Cabean Rt 2/1 Mangunsari & - \\
\hline 33 & Yofron & Jl. A. Yani & 820 \\
\hline 34 & Adnan Safii & Jl. Dr. Muwardi 49a & 820 \\
\hline 35 & Suratmi & Jl. Imam Bonjol 752 & $\mathbf{3 4 , 0 2 0}$ \\
\hline \multicolumn{2}{|c|}{ J u m I a h } & & \\
\hline
\end{tabular}

Sumber : Data Primer diolah

C. Analisis Data

1. Dari tabel data diatas bisa diperbandingkan bahwa kuota distribusi minyak tanah bersubsidi di Salatiga sebesar 138.800 liter, realisasi distribusi minyak tanah ke pangkalan hanya sebesar 34.020 liter berarti selisih kuota dengan realisasi sebesar ( 104.780) liter, jadi ada penyimpangan distribusi sebesar 75,49\%, akibatnya disini terjadi dampak kelangkaan minyak tanah dan kenaikan harga bahan bakar minyak tanah bersubsidi diatas harga eceran tertinggi (HET) yang ditetapkan oleh Pemerintah.

2. Dari uji beda diperoleh hasil uji t-tes (: lihat lampiran 1), dimana to (tobservasi) (dengan $\alpha=5 \%, \mathrm{db}=\mathrm{n}-1=35-1=34$ ) $=2,54$, setelah dikonsultasikan dengan $\mathrm{t}$ tabel (dengan $\alpha=5 \%, \mathrm{db}=\mathrm{n}-1=35-1=34)=$ 2,032, to $>$ tt ( $\mathrm{t}$ observasi $>\mathrm{t}$ tabel), dimana perbedaan ini secara statistik tidak sama dengan nol, sehingga ada perbedaan secara signifikan distribusi minyak tanah bersubsidi sebelum dan sesudah ada program konversi ke LPG.

\section{F. KESIMPULAN}

1. Distribusi Minyak Tanah Bersubsidi setelah ada konversi ke LPG yang ada di Kota Salatiga belum memenuhi harapan warga masyarakat Salatiga, dari analisis data diketahui bahwa distrbusi minyak tanah bersubsidi kuotanya tidak sama dengan realisasi penyalurannya, dimana kuota sebesar 138.800 liter, sedangkan realisasinya sebesar 34.020 liter sehingga ada penyimpangan sebesar 104.780 liter atau 75,49\%. 
2. Dari penyimpangan sebesar $75,49 \%$ tersebut dampaknya akan merugikan masyarakat miskin yang membutuhkan dan akan mengakibatkan kelangkaan minyak tanah yang ada di kota Salatiga.

3. Dari perhitungan uji beda diperoleh hasil $\mathrm{t}$ observasi $>\mathrm{t}$ tabel $=2,54>$ 2,032 berarti ada perbedaan yang signifikan distribusi minyak tanah bersubsidi sebelum dan sesudah adanya program konversi ke LPG.

\section{G. SARAN}

Dari kesimpulan hasil penelitian diatas, Peneliti memberikan beberapa masukan sebagai berikut :

1. Bidang Pengawasan Pengendalian Barang Beredar Dinas Perindustrian dan Perdagangan perlu melakukan pengawasan terhadap distribusi Minyak tanah bersubsidi secara rutin, sehingga barang tidak didistribusikan ke pihak yang tidak berhak.

2. Disperindag harus melarang pangkalan yang mendistribusikan minyak bersubsidi ke sesama pangkalan, kalau hal ini terjadi maka Pemerintah wajib mencabut ijin pangkalan.

3. Pemerintah wajib menelusuri penyimpangan distribusi minyak tanah bersubsidi, sehingga kalau memang benar-benar menyimpang Agen perlu diberi teguran/sanksi.

4. Peneliti lanjutan diharapkan bisa meneliti dampak lain sebagai akibat diberlakukannya program konversi minyak tanah ke LPG.

\section{DAFTAR PUSTAKA}

DH Basu Swatha, 1998 Azas - Azas Marketing, Lyberty, Yogyakarta. 1991, Saluran Pemasaran, BPFE, Yogyakarta.

DH Basu Swastha dan Irawan, 2005, Manajemen Pemasaran Modern, Edisi ke 2 Cetakan 12, Liberty, Yogyakarta.

Gubenur Jawa Tengah, 2007. Peraturan Gubenur Jawa Tengah Nomor 44 tahun 2007 tentang Pedoman Distribusi Minyak Tanah Bersubsidi di Propinsi Jawa Tengah. 
Gubernur Jawa tengah, 2005. Peraturan Gubenur Jawa Tengah Nomor 65 Tahun 2005 tentang Penetapan Harga Eceran Tertinggi (HET) minyak Tanah di Pangkalan Wilayah Propinsi Jawa tengah.

Gubenur Jawa Tengah, 2005, Peraturan Gubenur Jawa Tengah No. 63 tahun 2005 Tentang Penetapan Harga Eceran Tertinggi (HET) Minyak Tanah Nasional Tahun 2005.

Supranto.J, 1990, Teknik Pemasaran dan Ramalan Penjualan, Rineka Cipta, Jakarta.

Sugiyono, 2003 , Metode Penelitian Bisnis, Cetakan 5, Alfabeta, Bandung.

www.pertamina.com 
